\title{
Hernán Cortés y su relación epistolar con Carlos V: el fiel vasallo "al servicio de $\mathrm{Su}$ Majestad"
}

\section{Hernán Cortés and his Relationship with Charles V: the Loyal Vassal "in the Service of His Majesty"}

\author{
Guadalupe Gómez-Aguado de Alba ${ }^{1}$ \\ Universidad Nacional Autónoma de México (México)
}

ORCID: https://orcid.org/0000-0001-8366-2699

Recibido: 06-06-2021

Aceptado: 21-06-2021

\section{Resumen}

Hernán Cortés, el conquistador de México, llevó a cabo sus conquistas entre 1519 y 1525 . En esos años mantuvo una intensa relación epistolar con el emperador Carlos V, a quien dirigió sus Cartas de relación y muchas otras cartas y memoriales. A su vez, el emperador premió a Cortés con vasallos, títulos y honores. Sin embargo, al pasar de los años, cuando Cortés se estableció en la Nueva España, esa relación epistolar, que al principio fue muy fructífera, al final se convirtió en una molestia por las continuas quejas y reclamos del conquistador. Así, entre 1530 y 1547, después de los años de gloria, la relación entre Cortés y el monarca se tornó lejana y complicada. En este trabajo se analizan algunas de las cartas que Hernán Cortés envió al emperador y se hace una reflexión sobre la importancia de su figura en la España del siglo XVI, así como la relevancia de una relación, la del emperador y el conquistador, que cambió la faz del mundo entonces conocido.

Palabras-clave: conquista, México Tenochtitlan, Carlos V, Hernán Cortés, España.

\footnotetext{
${ }^{1}$ (gucega@unam.mx) Doctora en Historia por la Facultad de Filosofía y Letras de la Universidad Nacional Autónoma de México. Profesora de tiempo completo en el Centro de Enseñanza para Extranjeros de la UNAM. Ha publicado: "La conquista como 'admirable epopeya' o el origen del mestizaje en el México porfiriano", en 1521. La conquista de México en el arte, México, UNAM, 2020, pp. 127-141; "Hernán Cortés en el siglo XIX: la construcción de un mito entre la admiración y el rechazo", en Hernán Cortés en el siglo XXI. V Centenario de la llegada de Cortés a México, 2021, pp. 1099-1119; "La novela corta La quinta modelo o de cómo conjurar los peligros de la anarquía", en Gustavo Jiménez Aguirre y Verónica Hernández Landa Valencia (eds.), Ligera de equipaje. Itinerarios de la novela corta en México, México, UNAM, 2019. pp. 209-222.
} 


\begin{abstract}
Hernán Cortés, the conquistador of Mexico, conquered Mesoamerican territories between 1519 and 1525. Over the course of those years he maintained an intense epistolary exchange with the Emperor Charles V, to whom he wrote his Cartas de relación (Letters of Relation) and many other letters and memories. In return, the emperor rewarded Cortés with vassals, titles and honors. However, as time passed, when Cortés established his home in the New Spain, the epistolary exchange, which was so fruitful at the beginning, in the end became a nuisance for Charles $\mathrm{V}$ because of the constant complaints of the conquistador. As a consequence, between 1530 and 1547, after the glorious years, the relationship between Cortés and the monarch became estranged and complicated. This paper analyzes some of the letters Cortés sent to the emperor, and reflects on the importance of his figure in 16th century Spain, as well as the relevance of a relationship, that of the emperor and the conquistador, that changed the face of the known world.
\end{abstract}

Keywords: conquest, México Tenochtitlan, Charles V, Hernán Cortés, Spain

\footnotetext{
"Cortés soy, el que venciera

por tierra y por mar profundo

con esta espada otro Mundo

si otro mundo entonces viera.

Di a España triunfos y palmas

con felices, santas guerras.

Al rey, infinitas tierras...

A Dios, infinitas almas."

Lope de Vega
}

\title{
Hernán Cortés y la creación de un personaje
}

Desde que comenzaron a circular en Europa las relaciones que Hernán Cortés envió a Carlos v para dar a conocer sus hallazgos y conquistas, el extremeño se convirtió en un personaje central de la aventura que cambió la faz del mundo hasta entonces conocido. La biografía de Cortés, nacido en 1484 en Medellín, provincia de Extremadura, quedó ligada inexorablemente con la del monarca a quien dirigió todas sus relaciones y de quien siempre esperó recibir mercedes y reconocimiento. No obstante, la relación entre ambos personajes estuvo llena de altibajos y decepciones.

Sobre Hernán Cortés se ha escrito mucho en ambos lados del océano, ya que es un personaje ineludible en los estudios sobre la conquista y colonización 
del continente americano. En cuanto a las obras historiográficas, ha sido objeto de múltiples estudios, entre los que destacan los más recientes trabajos de José Luis Martínez y Juan Miralles en México, y los de Esteban Mira Caballos, Beatriz Aracil y Carmen Martínez Martínez en España ${ }^{2}$. Pero la bibliografía sobre él comenzó a escribirse desde el siglo XVI y a partir de entonces se convirtió en personaje central de las crónicas de Indias, tanto como en los relatos que se han escrito sobre los hechos de la conquista en los cinco siglos que han transcurrido desde entonces.

El mismo Hernando Cortés fue el creador de su imagen. En sus escritos, especialmente los de índole pública, como las Cartas de relación, Cortés configuró una imagen heroica de sí mismo, en la que confluyen rasgos del mundo clásico, medieval y renacentista. El extremeño fue un hombre entre varios mundos, no sólo entre la edad Media y el Renacimiento, sino también entre América y Europa, entre el Viejo y el Nuevo Mundo. Las cartas de Cortés reflejan la fascinación por todo lo que le fue revelado, pero también la búsqueda en ese entorno de referencias que le recordaran su tierra de origen. Así, trasladó a América nombres, paisajes, imágenes de lo conocido mientras trataba de asimilar lo que era inédito a sus ojos. Por lo demás, sus cartas tuvieron una intención propagandística en el sentido de "lo que tiene que ser propagado" e intentaron convencer a su emperador de sus buenas intenciones, de su lealtad a toda prueba ${ }^{3}$. A decir de José Luis Martínez,

El Cortés que descubre y conquista tierras remotas; el que describe a su rey las particularidades y costumbres de esas tierras y pueblos, cuya cultura le interesa y admira; el constructor de ciudades y el organizador de industrias y cultivos; el que buscaba gloria y fama, y aun el político razonador y realista, es un hombre de la nueva edad del mundo, un renacentista. Pero necesariamente, sus nociones, creencias, ideales y costumbres seguían siendo las que recibió de su tiempo y circunstancia, eran tradicionales, que históricamente se llaman medievales ${ }^{4}$.

En la escritura cortesiana vamos a encontrar siempre la intención de complacer y honrar a su interlocutor, de exaltar las propias hazañas para obtener el favor real, pero también emergerá la idea de España y del imperio como el

\footnotetext{
2 José Luis Martínez, Hernán Cortés, México, 2a . ed., Fondo de Cultura Económica, 2003; Juan Miralles, Hernán Cortés. Inventor de México, México, Tusquets, 2001; Esteban Mira Caballos, Hernán Cortés. Una biografía para el siglo XXI, Barcelona, Crítica, 2021; Beatriz Aracil Varón, "Yo, don Hernando Cortés". Reflexiones en torno a la escritura cortesiana, Navarra, IberoamericanaVeuvert, 2016; Hernán Cortés, Cartas y memoriales, edición, estudio y notas María del Carmen Martínez Martínez, Valladolid, Consejería de Cultura y Turismo, León, Universidad de León, 2003. Si bien la historiografía cortesiana es muy extensa, las obras de José Luis Martínez y María del Carmen Martínez y Martínez contienen un exhaustivo trabajo de rescate de las fuentes relativas al extremeño.

${ }^{3}$ Aracil, op. cit. [Edición electrónica].

${ }^{4}$ Martínez, op. cit., pp. 837-838.
}

Araucaria. Revista Iberoamericana de Filosofia, Política, Humanidades y Relaciones Internacionales, año $23, \mathrm{n}^{\circ} 47$. Segundo cuatrimestre de 2021. Pp. 69-90. ISSN 1575-6823 e-ISSN 2340-2199 https://dx.doi.org/10.12795/araucaria.2021.i47.04 
marco en que las acciones del extremeño formarán parte de un todo mucho mayor que él: la honra y la gloria del gran imperio español. En ese sentido, la identidad española como nación histórica a la que se refiere Pedro Insua existió como imperio desde los tiempos de Alfonso x, y se consolidó con la unión dinástica de Isabel de Castilla y Fernando de Aragón, bajo cuyo régimen se unirían los distintos reinos peninsulares. Cuando Carlos, nieto de los Reyes Católicos, accedió al trono español, se convirtió en rey de España y en 1520, emperador del Sacro Imperio Romano Germánico ${ }^{5}$. De ese modo, en los años en que Hernán Cortés emprendió su aventura americana, Carlos ya ocupaba la corona de España y a él dirigió sus Cartas de relación, en las que narró con lujo de detalles los avatares y los triunfos de la conquista de México ${ }^{6}$. Por lo que respecta a los documentos escritos por el extremeño, conocemos multitud de instrucciones, ordenanzas, memoriales, demandas, probanzas, contratos, cartas personales y hasta su testamento. Es decir, legó a la posteridad un corpus documental que no ha sido estudiado en su totalidad ${ }^{7}$.

El emperador Carlos v, nacido en 1500, accedió al trono español en marzo de 1516 y lo ocupó hasta enero de 1556. El joven monarca rondaba los 20 años cuando comenzó a recibir las relaciones de Cortés y, tal como lo afirma Beatriz Aracil, su figura ejerció una verdadera fascinación sobre él y sobre sus acciones, que fueron un intento del conquistador de "compartir con su monarca una suerte providencial"». Por otra parte, también debió justificar todo lo que

\footnotetext{
${ }^{5}$ De acuerdo con Pedro Insua, "infinidad de documentos, desde literarios hasta jurídicos, hablan durante la Edad Media de España como una sociedad que, si bien no está claramente definida desde el punto de vista político, sí tiene una identidad los suficientemente consistente como nación histórica [...] como para distinguirla de otras sociedades de rango semejante". Pedro Insua, 1492. España contra sus fantasmas, Barcelona, Ariel, 2018. [Edición electrónica]. Sobre el nacionalismo en España, Horst Pietschman afirma que España como concepto se usaba desde la baja Edad Media durante el reinado de los Reyes Católicos. Véase Horst Pietschman, “El problema del 'nacionalismo’ en España en la Edad Moderna. La resistencia de Castilla contra el emperador Carlos v", en Hispania, 180 (1992), pp. 83-106. Por su parte, Victor Frankl alude a José A. Maravall para afirmar que la concepción de imperio particular dentro de una concepción española se forma desde el siglo IX y destaca la unidad de España desde la Reconquista. Véase Victor Frankl, "Imperio particular e imperio universal en las cartas de Hernán Cortés” en Cuadernos Hispanoamericanos, 165 (1963), p. 445.

${ }^{6}$ Las conocidas como Cartas de relación de Hernán Cortés fueron bautizadas así por Enrique de Vedia en la edición de 1852. Cortés las llama simplemente relaciones. La primera que se publicó fue la Segunda relación en 1522, impresa en Sevilla y entre 1519 y 1523 escribió las cinco relaciones, de las que se conocen solamente cuatro, ya que la primera no ha sido encontrada en los archivos. En las ediciones de las Cartas se incluye la conocida como carta del cabildo, que sustituye a la primera relación. Para un estudio de todas las ediciones de las Cartas de relación, véase Ángel Delgado, "Noticia bibliográfica", en [Hernán Cortés: Cartas de relación, Barcelona, Castalia, 2016], pp. 73-89. Para este trabajo se usa esta edición comentada.

7 Martínez Martínez, op. cit., p. 19. María del Carmen Martínez afirma que "Cortés libró más batallas ante la justicia que durante las empresas de conquista". Y en ese sentido, muchos de los documentos que se conocen de su puño y letra son casos judiciales. Véase María del Carmen Martínez Martínez, "Más pleitos que convenía a su estado", en [María del Carmen Martínez Martínez y Alicia Mayer coords: Miradas sobre Hernán Cortés, Madrid, Iberoamericana-Veuvert, 2016], pp. 87-118.

8 Aracil cita a Manuel Fernández Álvarez, que definió como "la seducción de Carlos v" la fascinación que ejercía sobre los conquistadores ese joven emperador. Beatriz Aracil, "El monarca,
} 
hizo a partir de que se adentró en territorio continental, porque emprendió la conquista sin la autorización del gobernador de Cuba, Diego Velázquez, es decir, sin la anuencia real ${ }^{9}$.

Por lo demás, hay que tomar en cuenta que las acciones de Hernán Cortés estuvieron guiadas por su formación, sus creencias y su origen. La guerra de conquista que emprendió en tierras americanas fue, en muchos sentidos, una transposición de la Reconquista española. Así, al ver los templos prehispánicos en sus cartas los llamó mezquitas y en las batallas tuvo la ayuda del apóstol Santiago, que de Matamoros pasó a ser Mataindios. Tanto él como sus hombres nacieron en una sociedad organizada para la guerra, como lo afirma Bernard Grunberg, y los hidalgos guerreros como Cortés buscaron en el Nuevo Mundo una vida mejor, de modo que, tal como sus antepasados en las luchas contra los infieles, trataron de sacar todo el provecho posible de la conquista. Además, Cortés también era un humanista, un hombre del Renacimiento ávido de conocer y experimentar cosas nuevas ${ }^{10}$.

El conquistador extremeño, al igual que muchos de sus hombres, también estaba influenciado por los libros de caballería, textos llenos de aventuras y romances. Esos relatos, aparentemente auténticos, llenaron la imaginación de los aventureros españoles que esperaban encontrar lugares fantásticos, fabulosas riquezas, monstruos y encantamientos. En ese sentido, como afirma Irving Leonard, "el hecho mismo de la conquista fue rodeado de un espíritu caballeresco y romántico que [...] dio a estas expediciones un carácter totalmente distinto del que tienen empresas similares llevadas a cabo por otras naciones" 11 .

Cortés, convertido en el héroe de su propia narración, se caracterizó, de acuerdo con Aracil, por cuatro aspectos esenciales: "el militar, que lo define como singular conquistador; el referido al gobierno del territorio conquistado; el que marca su relación de vasallaje ante el rey y, por último, el religioso, que le permite mostrarse como un elegido de Dios"12. De modo que en las Cartas de Relación podremos encontrar las hazañas militares narradas en propia voz de don Hernán; sus ideas de gobierno, simbolizadas por su conocimiento y respeto a la ley y por el proyecto político y económico que emprendió en cuanto logró vencer a los mexicas y conquistar la ciudad de México-Tenochtitlan; su lealtad y

su vasallo y el otro: Hernán Cortés y los vínculos de la escritura”, en [Sonia Mattalia, Pilar Celma y Pilar Alonso, eds: El viaje en la Literatura Hispanoamericana: el espiritu colombino, Valladolid, Iberoamericana Vervuert, 2008] p. 148.

${ }^{9}$ Ibid., p. 149.

${ }^{10}$ Bernard Grunberg, "Hernán Cortés: un hombre de su tiempo", en [María del Carmen Martínez Martínez y Alicia Mayer coords: Miradas sobre Hernán Cortés, Madrid, Iberoamericana-Veuvert, 2016], pp. 51-53.

${ }^{11}$ Irving A. Leonard, Los libros del conquistador, 2a . ed., México, Fondo de Cultura Económica, 2006, p. 70.

12 Aracil, Yo, Don Hernando Cortés. [Edición electrónica]. 
fidelidad al rey más allá de cualquier duda y pese a perder el reconocimiento de Carlos v, y finalmente, su imagen como instrumento de la Providencia divina, simbolizada por las victorias militares que no podrían haberse logrado sin el favor de Dios. De esa manera, Cortés "se inscribe a sí mismo en la Historia como héroe que conquista una gran nación para su emperador y la gobierna con justicia"13.

En cuanto a las Cartas de relación, el medio por el cual Cortés ingresa en la historia desde época muy temprana, debe tomarse en cuenta que las escribió conforme iban ocurriendo los acontecimientos narrados. En ese sentido, son crónicas que describen los sucesos casi inmediatamente después de que estos ocurrieron. A diferencia de una obra historiográfica que es un análisis posterior de lo sucedido, Cortés fue narrando sus peripecias sin saber lo que ocurriría más adelante. Al enviar la Segunda relación, después de la derrota de la Noche Triste y la expulsión de México Tenochtitlan, aún era incierto su futuro y no sabía si podría conquistar la gran ciudad indígena. Y, sin embargo, estaba seguro de contar con el favor de la Providencia y por ello, creía que saldría triunfador de la aventura. Además, el destinatario concreto de las cartas era el rey Carlos, a quien se dirigieron los escritos de Cortés con la intención de que sus actos fueran aprobados y apoyados por el emperador. En ese sentido, como afirma Ángel Delgado, son "ejemplos paradigmáticos de historia viva"14.

\section{Una relación epistolar que busca exaltar la magnitud de la hazaña cortesiana en el marco de la grandeza española}

Hernán Cortés dejó para la posteridad no sólo sus Cartas de relación sino también, como se mencionó antes, un abundante corpus documental ${ }^{15}$. A través de la lectura de sus cartas y documentos es posible conocer la mentalidad, las ideas, los proyectos y los afanes del extremeño. Y también podemos asomarnos a la relación epistolar que mantuvo con el emperador Carlos v, en la que plasmó su intención de conquistar y poblar la tierra, siempre a nombre del rey y para

\footnotetext{
13 Idem.

14 A decir de Ángel Delgado, las Cartas de relación no deben juzgarse como productos de la fantasía desbordada del extremeño o como ficción pura, porque son documentos públicos y legales que pudieron usarse como declaración jurada, y de hecho así se usaron en el juicio de residencia de Cortés. Delgado, op. cit., pp. 53-56.

15 José Luis Martínez acompañó su biografía del extremeño con cuatro tomos de documentos cortesianos: José Luis Martínez, ed., Documentos cortesianos I 1518-1528. Secciones I a III, México, Fondo de Cultura Económica, UNAM, 2014 [edición electrónica]; José Luis Martínez, ed., Documentos cortesianos II 1526-1545. Sección IV. Juicio de Residencia, México, Fondo de Cultura Económica, UNAM, 2014 [edición electrónica]; José Luis Martínez, ed., Documentos cortesianos III 1528-1532. Secciones V a VI 1 ${ }^{a}$. parte, México, Fondo de Cultura Económica, UNAM, 2014 [edición electrónica]; José Luis Martínez, ed., Documentos cortesianos IV 1533-1548. Secciones VI, $2^{a}$ parte a VIII, México, Fondo de Cultura Económica, UNAM, 2014 [edición electrónica].
} 
gloria de España. Los primeros documentos conocidos, sin firma de Cortés, son la Carta de Veracruz, que se incluye en las cinco relaciones enviadas al monarca como sustituto de la hasta ahora perdida Primera relación, y las Instrucciones de Hernán Cortés a los procuradores Francisco de Montejo y Alonso Hernández Portocarrero. Ambos documentos, de acuerdo con Aracil, formaron parte de una estrategia de justificación por haber desobedecido las órdenes del gobernador de Cuba, Diego Velázquez, quien había enviado la expedición a reconocer el territorio y comerciar con los naturales, y no a conquistar y poblar. Y están firmados por los hombres de Cortés, de quien se hace referencia en tercera persona ${ }^{16}$. No fue sino hasta la Segunda carta de relación cuando apareció el "yo" en las misivas dirigidas al monarca. Pero fuera en boca de sus hombres, o en primera persona, "[la] firme creencia de [Cortés] en que la conquista respondía al fiel cumplimiento de un imperativo cristiano e imperial está presente del principio al fin de ellas", como asegura Ángel Delgado ${ }^{17}$.

Es posible que la Carta de Veracruz ${ }^{18}$ haya sido diseñada por don Hernando, aunque no aparezca como firmante, ya que se exaltan su servicio a la Corona y sus dotes de liderazgo ${ }^{19}$. Fechada en julio de 1519, describió también los descubrimientos previos al desembarco en las costas de lo que hoy es México, la organización de la expedición y la exploración de Yucatán, el Golfo de México y, finalmente, la fundación de Veracruz, algo muy importante porque esa estratagema lo independizó totalmente de la tutela de Diego Velázquez. Así, al final de la carta se incluyó un alegato para justificar su desobediencia al gobernador de $\mathrm{Cuba}^{20}$. La carta de Veracruz o Primera relación está dirigida a la reina Juana y a su hijo Carlos, ya para entonces rey de España, pero aún no emperador. Los firmantes los llamaron "altos", "poderosos", "excelentísimos príncipes", "muy católicos y muy grandes reyes y señores", y aseguraron que les harían saber los beneficios que tendrían de las tierras recién descubiertas y los servicios que recibirían por su conquista ${ }^{21}$. Suplicaban que Diego Velázquez no fuera nombrado gobernador ni adelantado, porque aseguraban que no convenía al servicio de la corona, ya que su ambición era tanta, que no entregaría el oro y la plata obtenidos hasta entonces, sino que se los apropiaría para su propio beneficio. También acusaron a Velázquez de maltratar a sus hombres, de tenerlos sumidos en la pobreza y de no entregarles indios para su servicio. En ese documento solicitaron a los reyes que nombraran a Hernando Cortés capitán

\footnotetext{
16 Aracil, Yo, don Hernando Cortés. [Edición electrónica]

17 Delgado, op. cit., 37.

${ }^{18}$ En la edición de Ángel Delgado se llama Carta de Veracruz al documento que ha sustituido a la Primera relación. José Luis Martínez, por su parte, la llama Carta del cabildo.

${ }^{19}$ Así lo creen Delgado y Martínez. Véase Delgado, op. cit., p. 47; Martínez, Hernán Cortés, p. 149.

20 Martínez, Hernán Cortés, p. 149.

${ }^{21}$ Hernán Cortés, Cartas de relación, pp. 105-106.
} 
y justicia mayor, por ser "la persona que conviene para ello". Finalmente, se declararon leales vasallos, como lo habían sido y lo serían siempre ${ }^{22}$.

Para reforzar esa impresión que se quería dar a los monarcas, Cortés envió las Instrucciones mencionadas líneas arriba, en las que los integrantes del Cabildo decían:

[...] quel dicho Fernando Cortés era persona tal cual para el dicho cargo [de Capitán General], muy celoso e deseoso del servicio de sus majestades, e los cargos e oficios reales que en estas islas ha tenido y en estas partes y en ellos haber dado muy buen cuenta y servido a Sus Reales Altezas en ellos, e ser muy bien quisto [...] e que de servir a la dicha corona real era todo su pensamiento [...]. Sabéis e conocéis a Hernando Cortés y es notorio cuánto celo tiene a las cosas del servicio de Dios Nuestro Señor e con cuán entera y sana voluntad ha servido e sirve a la corona real e cuánta habilidad y suficiencia tiene para dar muy buena cuenta de todo e cualesquier cargos que por Sus Reales Altezas le fueren encomendados $[\ldots]^{23}$.

Así, desde el inicio del intercambio epistolar, Cortés hizo gala de su lealtad a la corona, de su afán de servicio, de su fe y su intención de llevar la religión católica a las tierras recién descubiertas. Si bien su firma no estaba en esos documentos, era clara la intención de que sus hombres dejaran muy claro que él debía encabezar el proceso de descubrimiento y conquista, y que no había mejor hombre para dirigir la aventura. Además, mientras se adentraba en el territorio americano, Cortés dejaba en claro al rey que su intención era que los indígenas que iba encontrando en su periplo se convirtieran en vasallos de la corona, es decir, estaba "instaurando el dominio regio sobre el territorio" $" 24$.

La Segunda relación ya fue escrita en primera persona y firmada por don Hernando. Es la carta que describe las peripecias de la marcha hacia México Tenochtitlan, la estancia en la capital mexica, el encuentro con los hombres de Pánfilo de Narváez, la huida de la ciudad y la derrota de la Noche Triste. Esta relación, muy detallada y llena de descripciones del entorno, es muy significativa porque en ella, de acuerdo con el tono de la narración, el extremeño ya se percibía plenamente capaz de conquistar la tierra a nombre de España. La carta se puede dividir en tres grandes temas: "la descripción de un horizonte señorial indígena, la entrega del reino y finalmente la justificación de la conquista" 25 .

\footnotetext{
22 Ibid., pp. 146-149.

23 “Instrucciones de Hernán Cortés a los procuradores Francisco de Montejo y Alonso Hernández Portocarrero enviados a España”, Veracruz, julio de 1519, en Martínez, Documentos cortesianos I, documento 4. [Edición electrónica].

${ }^{24}$ Miguel Ángel Segundo Guzmán, “Grafías del Conquistador: horizontes de significado señorial en las ‘Cartas de relación’ de Hernán Cortés” en Historia y Grafia, 23 (2016), p. 192.

25 Ibid., p. 193.
} 
En el preámbulo de la Segunda relación Cortés escribió a Carlos v que quería que supiese de las cosas de esa tierra "que son tantas y tales que, como ya en la otra relación escribí, se puede intitular de nuevo Emperador della y con título y no menos mérito que el de Alemaña que por la gracia de Dios Vuestra Sacra Majestad posee”. Además, enfatizó que los señores de los sitios recorridos hasta entonces, "han ofrecido su serviscio y dádose por sus súbditos y vasallos" 26. De manera que los indígenas que Cortés iba encontrando en su camino hacia la ciudad de México Tenochtitlan, de acuerdo con lo que afirma el extremeño, se sometían de buen grado a la autoridad real y a un gran señor que habitaba allende el mar.

En el camino rumbo a Tenochtitlan, Hernán Cortés fue renombrando las ciudades indígenas con nombres españoles. Así, a Cempoala la llamó Sevilla, a Tlaxcala la comparó con Granada, Tenochtitlan era tan grande como Córdoba. Tal como afirma Miguel Ángel Segundo, para explicar el Nuevo Mundo a su interlocutor era necesario compararlo con imágenes conocidas. En ese sentido, la apropiación de espacios para ponerlos bajo la égida de la corona se hizo bajo esquemas legales que imperaban entonces en Europa. Es evidente que los avances sobre territorio americano implicaron la toma de posesión simbólica, la ocupación material mediante el sometimiento de los nativos de esas tierras y la repoblación del territorio. En cuanto a la primera, implicó el reconocimiento y registro en los relatos de viaje, el dar nuevos nombres a los lugares ocupados y llevar a cabo un registro cartográfico de los mismos. De ese modo, los conquistadores no sólo bautizaron los sitios ocupados, sino que cambiaron los nombres indígenas de acuerdo con lo que escuchaban de un idioma completamente desconocido para ellos. Es decir, desde el primer contacto, comenzó a transformarse el entorno, primero simbólicamente y más adelante con la construcción de ciudades y villas a la manera española ${ }^{27}$.

En cuanto a la narración de Cortés sobre el recorrido por territorio mesoamericano rumbo a México Tenochtitlan, cuenta que en los sitios a los que llegaba siempre encontraba pueblos sometidos al poder de Moctezuma, el tlatoani mexica. Al preguntar si eran sus vasallos, le respondían que todos lo eran, "queriendo decir que allí era señor del mundo". Para combatir esa idea, don Hernando explicaba a los indígenas el gran poder del rey de España y que "otros muy muchos y muy mayores señores que no Muteecuma eran vasallos de Vuestra Alteza [...] y que ansí lo había de ser Muteecuma y todos los naturales destas tierras" 28 . Por otra parte, sus hombres no las tenían todas

\footnotetext{
${ }^{26}$ Cortés, Cartas de relación, p. 161. Se respeta la ortografía de las relaciones de Cortés tal como se reproducen en la edición de Ángel Delgado (N. de la A.).

27 Flor Trejo Rivera, Guadalupe Pinzón Ríos, "Tomas de posesión simbólicas de los espacios americanos: la manera de reclamar derechos sobre territorios recorridos u ocupados por los castellanos desde el siglo XVI", Noticonquista, http://www.noticonquista.unam.mx/index.php/ amoxtli/1323/1318. Visto el 25/05/2021.

${ }^{28}$ Cortés, Cartas de relación, p. 171.
} 
consigo, y muchas veces solicitaron al extremeño volverse a su tierra por el temor que tenían de perder la vida en la aventura. Pero Cortés, siempre en sus propias palabras, los animaba diciéndoles

que eran vasallos de Vuestra Alteza y que jamás en los españoles en ninguna parte hobo falta, y que estábamos en disposición de ganar para Vuestra Majestad los mayores reinos y señorios que había en el mundo y que además de facer lo que a cristianos éramos obligados en puñar contra los enemigos de nuestra fee, y por ello en el otro mundo ganábamos la gloria y en éste consiguíamos el mayor prez y honra que hasta nuestros tiempos ninguna generación ganó; $y$ que mirasen que teníamos a Dos de nuestra parte y que a él ninguna cosa es imposible, y que lo viesen por las vitorias que habíamos habido, donde tanta gente de los enemigos eran muertos y de los nuestros ningunos" ${ }^{\prime 2}$.

En la cita que antecede desataca la idea de la identidad española, a la que apela Cortés para mantener unida a su hueste. También vemos el énfasis en ganar para el emperador reinos y señoríos de grandeza nunca vista, así como el sentido mesiánico de contar con el favor divino, ya que los guiaba la fe verdadera a la que convertirían a los indígenas en cuanto lograran conquistar la tierra. Así, a lo largo de la muy prolija narración cortesiana, vamos a ver a los tlaxcaltecas que decidieron aliarse con Cortés y que aceptaron ser fieles súbditos y vasallos del emperador, a quien ofrecieron para siempre "sus personas y haciendas". De ellos, afirmaba que eran "gente de toda razón y concierto" y que su gobierno era como "las señorías de Venecia y Génova o Pisa, porque no hay señor general de todos", sino muchos señores a los que se les rendía tributo ${ }^{30}$. Así vemos de nuevo cómo el narrador acudía a modelos conocidos para hacer inteligible su descripción de los hechos que le interesaba especialmente que conociera el rey Carlos. A lo largo de la Segunda relación iba apareciendo cada vez más nítidamente el conquistador como hombre indispensable, el líder del proyecto, el leal y fiel súbdito de la corona española que no buscaba honor y gloria para él, sino para España. Por supuesto, y como veremos más adelante, tras de la falsa humildad de su narración Cortés quería dejar muy claro que, si bien hacía todo a nombre de la monarquía, también buscaba reconocimiento y favores por las hazañas conseguidas. En ese sentido, era un hombre de su tiempo, que encaja perfectamente en la descripción de Irving Leonard: "dotado de tremendo coraje, de poderosa imaginación y de fanatismo religioso, y embriagado de triunfo por sus recientes victorias contra los infieles mahometanos, el conquistador fue el vehículo señalado para dominar un nuevo mundo e iniciar la occidentalización del globo"31.

${ }^{29}$ Ibid., p. 182. Las cursivas son mías. (N. de la A.).

${ }^{30}$ Ibid., pp. 183-185.

31 Leonard, op. cit., p. 59.

Araucaria. Revista Iberoamericana de Filosofia, Politica, Humanidades y Relaciones Internacionales, año $23, \mathrm{n}^{\circ} 47$. Segundo cuatrimestre de 2021. Pp. 69-90. ISSN 1575-6823 e-ISSN 2340-2199 https://dx.doi.org/10.12795/araucaria.2021.i47.04 
Y para un conquistador de ese tamaño, tenía que haber un gran señor a su altura, y es precisamente en la segunda carta en la que emerge la imagen de Moctezuma Xocoyotzin como el emperador del mundo indígena, aquel que fue vencido por Cortés y sometido a la autoridad de la corona española. El encuentro de Cortés y Moctezuma, cuando por fin sucedió, cobró una importancia fundamental en la narración del extremeño, ya que marcó la entrega simbólica del reino mediante el vasallaje al que supuestamente se sometió el señor mexica después de varios meses de convivencia forzada con Cortés y sus hombres. A decir de Beatriz Aracil, dado que Carlos v era el eje central de la escritura de Cortés, su presencia determinó la forma en que el mismo conquistador apareció retratado y también la manera en que explicó al indígena, especialmente al protagonista de los hechos más significativos, es decir, a Moctezuma ${ }^{32}$.

Cuando ambos personajes se encontraron, Cortés reprodujo el parlamento del señor de los mexicas en el que, según el extremeño, Moctezuma afirmó que

muchos días ha que por nuestras escripturas tenemos de nuestros antepasados noticia que yo ni todos los que en esta tierra habitamos no somos naturales della, sino extranjeros y venidos a ellas de partes muy estrañas. Y tenemos ansimesmo que a estas partes trajo nuestra generación un señor cuyos vasallos todos eran, el cual se volvió a su naturaleza [...] y siempre hemos tenido que los que dél descendiesen habían de venir a sojuzgar esta tierra y a nosotros como a sus vasallos, y según de la parte que vos decís que venís, que es hacia a do sale el sol, y las cosas que decís de ese grand señor o rey que acá os invió, creemos y tenemos por cierto él ser nuestro señor natural [...] y por tanto, vos sed cierto que os obedeceremos y ternemos por señor en lugar dese gran señor que decís, y que en ello no habrá fata ni engaño alguno. Y bien podéis en toda la tierra, digo que yo en la que en mi señorío poseo, mandar a vuestra voluntad, porque será obedescido y fecho" ${ }^{33}$.

Así, desde el primer encuentro entre Cortés y Moctezuma, supuestamente éste se sometió voluntariamente al rey de España y decidió obedecerlo, siempre desde el relato del extremeño. La imagen del señor de los mexicas quedó plasmada como la de un hombre sometido voluntariamente a un poder superior, en este caso, el del emperador español a quien rindió vasallaje. En este relato, Carlos v aparece como señor natural de los mexicas, representado de manera legítima por Cortés, y México se convierte en posesión del emperador por derecho de herencia. De ese modo, Cortés justificó la potestad de Carlos v sobre los territorios conquistados, que serían independientes del dominio castellano sobre las islas del Caribe, concedidas a la corona por "donación

32 Aracil, "El monarca, su vasallo y el otro", p. 150.

${ }^{33}$ Cortés, Cartas de relación, pp. 210-211. Las cursivas son mías. (N. de la A.). 
papal”34. Es evidente, tal como afirma Ángel Delgado, que el lenguaje del discurso que Cortés atribuyó a Moctezuma en realidad iba dirigido a su destinatario, a quien buscaba impresionar con la idea de que un rey pagano se sometía "providencialmente a su poderío" 35 .

De acuerdo con el relato cortesiano, Moctezuma fue hecho prisionero y quedó a merced del conquistador, se sometió al nuevo señor y fue asesinado por los suyos cuando ya no pudo controlar los acontecimientos. La Segunda relación buscaba dejar en claro que Cortés había recuperado a nombre del rey de España lo que por derecho le pertenecía, dado que el señor mexica ya era vasallo de Su Majestad. Finalmente, pese a la derrota y la huida de la ciudad después de la trágica muerte de Moctezuma y el ataque de los mexicas en contra de los españoles y sus aliados indígenas, Cortés confiaba en que saldría victorioso en su empresa y ya preparaba la toma definitiva de la ciudad mexica.

En el epílogo de la segunda carta Cortés le dice al emperador que "por lo que yo he visto cerca de la similitud que toda esta tierra tiene a España, ansí en la fertilidad como en la grandeza y fríos que en ella hace y en otras muchas cosas que la equiparan a ella, me paresció que el más conveniente nombre para esta dicha tierra era llamarse la Nueva España del Mar Océano, y ansí en nombre de Vuestra Majestad se le puso aqueste nombre"36. De ese modo, la tierra conquistada por el extremeño se convirtió en Nueva España, de acuerdo con los deseos del conquistador. De manera que al sugerir a Carlos V que se convirtiera en emperador de esa nueva entidad política llamada Nueva España, Cortés se deslindaba de Diego Velázquez y entraba en la órbita directa del monarca ${ }^{37}$.

En la Tercera relación se narra el cerco a Tenochtitlan y Cortés se describe a través de sus letras como un excelente estratega, astuto y valiente. En su narración enfatizó que la tierra no estaba pacificada aún y señaló la importancia de su figura para mantener el control de la población indígena. Además, informó al monarca sobre el descubrimiento del Mar del Sur ${ }^{38}$. Esta relación fue enviada al monarca junto con una misiva privada, ya que Cortés sabía que sus Cartas de relación eran documentos públicos a pesar de estar dirigidas al emperador. De modo que, a partir de entonces, envió al rey documentos privados para tratar asuntos que no quería difundir públicamente. En dicha comunicación, fechada en Coyoacán el 15 de mayo de 1522, el conquistador expuso su inquietud porque después de tres años en que siempre había "escrito y avisado" al rey

${ }^{34}$ Frankl, op. cit., pp. 450-452.

${ }^{35}$ Cortés, Cartas de relación, p. 210.

${ }^{36}$ Ibid., p. 308.

${ }^{37}$ Frankl, op. cit., pp. 454-459. A decir de Víctor Frankl, en este momento Cortés tenía una idea de imperio particular, basada en las Siete Partidas y en la historia medieval. A partir de la Tercera relación, su idea de imperio se transformará en una visión universal.

${ }^{38}$ Delgado, "Introducción", pp. 49.

Araucaria. Revista Iberoamericana de Filosofía, Politica, Humanidades y Relaciones Internacionales, año $23, \mathrm{n}^{\circ} 47$. Segundo cuatrimestre de 2021. Pp. 69-90. ISSN 1575-6823 e-ISSN 2340-2199 https://dx.doi.org/10.12795/araucaria.2021.i47.04 
"cosas que importaban mucho a su servicio", no había tenido respuesta ${ }^{39}$. Para tranquilidad de don Hernando, en octubre de ese mismo año recibió la buena nueva de su nombramiento como gobernador, capitán general y justicia mayor de las tierras conquistadas. Carlos v le decía:

[...] e acatando la suficiencia e habilidad de vos, Hernando Cortés, e que está aquí e al presente habéis estado en ella, e regido e gobernado la dicha tierra, e a vuestra suficiencia e mucha experiencia que tenéis della, e indios e moradores, e secretos della; e porque entendemos que ansí comple al servicio de vuestro señor e nuestro e de la conversión de los dichos indios a nuestra santa fé católica, que es nuestro principal fin, e a la ejecución de nuestra justicia e buena gobernación de las dichas tierras e islas, nuestra merced e voluntad es, que agora e de aquí en adelante, cuanto nuestra merced e voluntad fuese, hasta que nos mandemos proveer otra cosa, e sin perjuicio de cualesquier derecho quel adelantado Diego Velázquez o vos, el dicho Hernando Cortés, tengáis o pretendáis tener por el descubrimiento e conquista de la dicha tierra seáis nuestro gobernador e capitán general de toda la tierra e provincias de la dicha Nueva España $[\ldots]^{\prime 40}$.

A la cédula que hizo oficial el nombramiento de Cortés como gobernador de la Nueva España, Carlos v la acompañó con una carta en la que le daba instrucciones para el gobierno y le decía que sus Relaciones y las noticias sobre lo que pasaba en esas tierras las tenía por "cosa grande y señalada" y esperaba que Dios "fuera muy servido y su Santa Fe Católica ensalzada y acrecentada", lo que era su principal deseo. Además, finalmente reconoció lo mucho que Cortés había hecho para lograr la conquista, de lo que decía tenerse por muy servido. Además, el rey Carlos hizo énfasis en que confiaba en la lealtad del extremeño, por lo que había decretado su nombramiento como gobernante de esas tierras, siempre para el beneficio de la corona y en servicio de Dios. También pedía que los indios fueran "industriados e doctrinados, para que vengan en conocimiento de nuestra Santa Fe Católica, atrayéndolos para ello por todas las buenas mañas e buenos tratamientos que convenga, pues, a Dios Gracias, según vuestras Relaciones, tienen más habilidad y capacidad para que se haga en ellos fruto y se salven, que los indios de las otras partes que hasta agora se han visto, porque este es mi principal deseo e intención, y en ninguna cosa me podéis tanto servir"'41. En el intercambio entre Cortés y Carlos

39 “Carta de Hernán Cortés a Carlos v con la que enviaba su Tercera relación”, Coyoacán, 15 de mayo de 1522, en Martínez, Documentos cortesianos I, documento 21. [Edición electrónica].

40 "Real Cédula de nombramiento de Hernán Cortés como gobernador y capitán general de la Nueva España e instrucciones para su gobierno", Valladolid, 15 de octubre de 1522, en Martínez, Documentos cortesianos I, documento 25. [Edición electrónica].

41 "Carta de Carlos v a Hernán Cortés en que le da instrucciones para el gobierno de Nueva España y le anuncia el envío de oficiales reales", Valladolid, 15 de octubre de 1522, en Martínez, Documentos cortesianos I, documento 26. [Edición electrónica]. Las cursivas son mías (N. de la A.). 
v siempre apareció la cristianización de los indígenas como el propósito mayor de la conquista. El servicio a Dios y a la corona de España serían los principales motivos del dominio y pacificación de las tierras descubiertas.

En 1523 el emperador Carlos le envió a Cortés sus instrucciones para el trato justo a los indígenas y para la administración de la hacienda real. Entonces podemos ver que el monarca recomendó encarecidamente la prohibición de los sacrificios humanos y la práctica de la religión indígena. También dijo a Cortés que los indígenas no debían ser sujetos a la encomienda, ya que en las islas habían muerto la mayoría por esas prácticas. En cambio, el rey pedía a Cortés que los indios vivieran libres "como nuestros vasallos viven en estos nuestros reinos de Castilla", pero que se mantuviera el pago de tributo que ellos daban desde tiempos inmemoriales a sus gobernantes. Finalmente, pedía que no se les quitara lo que era suyo, que no se les hiciera la guerra, que se respetara a sus mujeres y se les tratara con amor y cuidado ${ }^{42}$. Como se ve, eran muy claras las instrucciones de gobierno del monarca para las tierras conquistadas. Sin embargo, Cortés desobedeció dichas instrucciones, ya que para él la encomienda era necesaria para mantener sujetos a los indígenas al servicio de los españoles.

En octubre de 1524 don Hernando envió al rey una carta que acompañaba la Cuarta relación, en la que en la que le explicaba por qué no había obedecido sus instrucciones. Entre otras razones, Cortés afirmó que, si se prohibieran las encomiendas, dejarían de llegar españoles a las nuevas tierras, "de lo que no poco daño se seguiría, así en lo que toca al servicio de Dios Nuestro Señor, cesando la conversión destas gentes, como en disminución de las reales rentas de Vuestra Majestad, y perderse tan gran señorío como en ellas Vuestra Alteza tiene". El conquistador también afirmaba que la encomienda era mejor que el estado en el que vivían antes los indígenas, que eran sacrificados en gran cantidad a sus "ídolos". En cambio, ya no se practicaban sacrificios y los indios eran mantenidos por los señores, que los cuidaban mucho por ser su fuerza de trabajo. Además, le hacía saber al monarca que el salario que le había asignado no era suficiente para su sostenimiento ${ }^{43}$. En dicha relación Cortés buscaba convencer al emperador de su eficacia como gobernador de los nuevos territorios ganados para la corona y exponía los muchos servicios prestados en su beneficio. Además, frente a la posible fiscalización de sus gastos por parte de los funcionarios reales enviados para tal fin, Cortés afirmaba que había hecho grandes gastos en las empresas de descubrimiento emprendidas y solicitaba al rey tener libertad para operar con manos libres para ensanchar los territorios y

42 "Instrucciones de Carlos v a Hernán Cortés sobre tratamiento de los indios, cuestiones de gobierno y recaudo de la Real Hacienda", Valladolid, 26 de junio de 1523, en Martínez, Documentos cortesianos I, documento 30. [Edición electrónica].

43 "Carta reservada de Hernán Cortés al emperador Carlos v, Tenustitan (sic.), 15 de octubre de 1524, en Martínez, Documentos cortesianos I, documento 36. [Edición electrónica]. 
señoríos de la corona ${ }^{44}$. En esa Cuarta relación aparece la idea de un imperio universal que trasciende las fronteras novohispanas, imagen que es muy evidente en la frase que Cortés dice al rey en la Cuarta relación a propósito de la construcción de navíos para la exploración del Mar del Sur: "tengo por muy cierto que con ellos, siendo Dios Nuestro Señor servido, tengo de ser cabsa que Vuestra Sacra Majestad sea en estas partes señor de más reinos y señoríos que los que hasta hoy en nuestra nación se tiene noticia [...] pues creo que con hacer yo esto no le quedará a Vuestra Excelsitud más que hacer para ser monarca del mundo" 45 .

En 1525 Cortés decidió emprender la ruinosa expedición a las Hibueras con el fin de castigar la rebelión de Cristóbal de Olid. Mientras iba rumbo al sur del territorio en una aventura por demás perjudicial para él y sus hombres, en la que casi perdió la vida por los sinsabores del accidentado camino, el Rey lo nombró adelantado de Nueva España, le dio el tratamiento de "don” y le otorgó un escudo de armas, algo que el propio Cortés había buscado con ahínco ${ }^{46}$. En la cédula respectiva, registró todos los servicios prestados a la Corona:

Por cuanto, por parte de vos, Hernando Cortés, nuestro gobernador y capitán general de la Nueva España y provincias della, nos fue hecha relación que entre muchos y grandes servicios que nos habéis hecho en la pacificación y población de la dicha Nueva España y provincias della, que dizque en tiempo de tres años sujestatses y aplicastes a nuestro servicio y señorío más de ochocientas leguas de tierra poblada de mucha gente que nos reconocen por supremos y universales señores [...] y nos, acatando los muchos trabajos y peligros y aventuras que en lo susodicho pasastes y porque de vos y de vuestros servicios quede perpetua memoria, y vos y vuestros descendientes seáis más honrados, por la presente vos hacemos merced [...] de un escudo, las cuales dichas armas vos damos $[\ldots]^{47}$.

Así, el emperador no sólo reconocía las hazañas de Cortés en la conquista, sino que enfatizaba el que los habitantes de las tierras conquistadas lo reconocían como su gobernante supremo; de ese tamaño era la gesta cortesiana.

La Quinta relación, fechada en septiembre de 1526, narra la fallida expedición a las Hibueras, la ejecución de Cuauhtémoc, el último tlatoani mexica y su regreso a la ciudad de México, en donde fue despojado de su título de gobernador y sometido a un juicio de residencia, que, por cierto,

${ }^{44}$ Delgado, "Introducción", p. 50.

${ }^{45}$ Cortés, Cartas de relación, p. 500; Frankl, op. cit., p. 459.

46 "Cédula de Carlos v a Hernán Cortés nombrándolo adelantado de Nueva España", Madrid, 7 de marzo de 1525, en Martínez, Documentos cortesianos I, documento 45. [Edición electrónica].

47 "Cédula de Carlos v a Hernán Cortés en que le concede escudo de armas", Madrid, 7 de marzo de 1525, en Martínez, Documentos cortesianos I, documento 46. [Edición electrónica]. Las cursivas son mías (N. de la A.). Este documento es un resumen de todos los hechos de la conquista. Es relevante porque en él el emperador hace un recuento de todos los hechos heroicos que Cortés le había narrado en sus relaciones de la conquista de México Tenochtitlan.

Araucaria. Revista Iberoamericana de Filosofía, Política, Humanidades y Relaciones Internacionales, año $23, \mathrm{n}^{\circ} 47$. Segundo cuatrimestre de 2021. Pp. 69-90. ISSN 1575-6823 e-ISSN 2340-2199 https://dx.doi.org/10.12795/araucaria.2021.i47.04 
quedó inconcluso. El tono de esta carta es triste y refleja la amargura de Cortés, que acusa a sus malquerientes de haber indispuesto al rey en su contra ${ }^{48}$. Así, afirmó que quienes habían dicho que él no iba a obedecer al rey habían mentido abiertamente. Decía que "si las verdaderas obras miraran y jueces justos fueran, muy al contrario lo debieran significar, porque hasta agora no se ha visto ni se verá en cuanto yo viviere ante mí o a mis noticias haya venido carta ni otro mandamiento de Vuestra Majestad Sancta que no haya sido, es y será obedescido y cumplido sin faltar en él cosa alguna [...]"49.

Esta última afirmación no es tan cierta, dado que el extremeño había desobedecido al rey en cuanto a la organización de la sociedad que se estaba formando, como se mencionó antes. También desobedeció un requerimiento del emperador que en noviembre de 1525 lo llamó para que acudiera a España, y finalmente hizo el viaje hasta abril de $1528^{50}$. Pero él nunca dejó de hacer gala de extrema lealtad y obediencia a las órdenes reales.

Los años que van de la toma de México Tenochtitlan a la expedición a las Hibueras, entre 1521 y 1526, son el escenario de la mayor gloria de Hernán Cortés. Como afirma Aracil, "Cortés [gozaba], pues, no sólo del poder en Nueva España sino de una estrecha relación con el rey"51. En 1520 emergió en la escena europea porque Carlos v decidió exponer en Bruselas los objetos enviados por el extremeño en su primera relación. El motivo de la exposición, llamada Tesoro de Moctezuma, fue la coronación del emperador. A raíz de eso, en 1522 apareció un folleto impreso que anunciaba novedades sobre un país llamado Yucatán. Muy pronto la Segunda carta de relación se publicó en Sevilla y fue un éxito editorial, tanto que se hicieron traducciones al francés, al italiano y al holandés. La tercera carta, también publicada en Sevilla en 1523, asombró a sus contemporáneos por el relato de la victoria de Cortés sobre el imperio de Moctezuma. Sin embargo, en España las cartas de don Hernando fueron prohibidas por las gestiones de Pánfilo de Narváez, quien consiguió que la corona expidiera una cédula prohibiendo la impresión y venta de las ediciones existentes. Después de esa cédula se quemaron todos los ejemplares. La corona, por su parte, estuvo de acuerdo en la suerte seguida por los escritos de Cortés, ya que deseaba evitar que se convirtiera en un héroe, fundador de un nuevo reino ${ }^{52}$. Así, desde fechas muy tempranas, Cortés fue un personaje incómodo para el rey Carlos, quien reconoció los servicios prestados a la monarquía, pero trató de controlarlo y no darle un papel protagónico en el gobierno de la Nueva España.

${ }^{48}$ Delgado, "Introducción", p. 51.

49 Cortés, Cartas de relación, pp. 648-649.

50 "Cédula de Carlos v a Hernán Cortés en que se le ordena que se traslade a España", Toledo, 24 de noviembre de 1525, en Martínez, Documentos cortesianos I, documento 49. [Edición electrónica].

${ }^{51}$ Aracil, "Yo, Don Hernando Cortés". [Edición electrónica].

${ }^{52}$ Karl Kohut, "Hernán Cortés, héroe imperial”, en [María del Carmen Martínez Martínez y Alicia Mayer coords: Miradas sobre Hernán Cortés, Madrid, Iberoamericana-Veuvert, 2016], pp. 67-68.

Araucaria. Revista Iberoamericana de Filosofia, Politica, Humanidades y Relaciones Internacionales, año $23, \mathrm{n}^{\circ} 47$. Segundo cuatrimestre de 2021. Pp. 69-90. ISSN 1575-6823 e-ISSN 2340-2199 https://dx.doi.org/10.12795/araucaria.2021.i47.04 


\section{Los años difíciles}

En 1528 Hernán Cortés regresó a España, mientras que en Nueva España se reinició su juicio de residencia. El extremeño fue acusado de infidelidad, desobediencia, crímenes y crueldades, excesos sexuales, enriquecimiento y apropiación de tierras y de la muerte de su primera esposa, Catalina Juárez. Los miembros de la Audiencia le impusieron multas, persiguieron a sus leales y lo despojaron de todos sus bienes. Paradójicamente, en España fue recibido por el rey, fue nombrado marqués del Valle de Oaxaca y se le otorgaron pueblos y vasallos. También fue designado capitán general de la Nueva España y del Mar del Sur, aunque ya nunca más volvería a ser gobernador de las tierras conquistadas $^{53}$.

Entre 1530 y 1540 Hernán Cortés regresó a la Nueva España, casado con Juana de Zúñiga, de origen noble. Así cumplió uno de sus objetivos: emparentar con la nobleza y estar más cerca de la élite de la época. Su regreso fue muy difícil, porque le prohibieron, por órdenes de la reina Juana, entrar a la Ciudad de México para no causar disturbios. Él y su séquito, entre quienes estaba su madre Catalina Pizarro, padecieron hambre y escasez, tanta que su madre murió por las privaciones y su esposa perdió a su primer hijo. Así lo narró el propio Cortés en carta dirigida al Consejo de Indias, en la que afirmó que "de hambre y de mal proveídos se han muerto los más y por no poderlos yo remediar a causa de no tener para mí; pues su Majestad y este Real Consejo lo tienen por bien, yo no tengo más que decir de conformarme con lo que mandaren, como siempre lo he hecho" ${ }^{54}$. En ese momento, en que Cortés estaba perdiendo su poder y su influencia en el gobierno de las tierras conquistadas, seguía haciendo gala de su obediencia y su lealtad.

En esos años el extremeño también enfrentó pleitos sin fin, mientras formó empresas de todo tipo: mineras, agrícolas, ganaderas. Hizo nuevas expediciones hacia el Pacífico y Baja California y finalmente, después de un abierto enfrentamiento con el primer virrey novohispano, Antonio de Mendoza, en 1540 regresó a España para no volver a la tierra que conquistó y a la que siempre quiso regresar. El pleito de Cortés con el virrey fue por el despojo de sus astilleros en Tehuantepec y por la prohibición de realizar más viajes de descubrimiento, mientras el mismo Mendoza mandaba hacia el norte del territorio novohispano sus propias expediciones. Así, instalado en Madrid, envió al rey un memorial para tratar de convencerlo de las malas intenciones del virrey, sin saber que éste tenía instrucciones de limitar los poderes de Cortés

\footnotetext{
${ }^{53}$ Martínez, Hernán Cortés, pp. 818-819.

54 "Carta de Hernán Cortés al licenciado Rodrigo de la Corte, del Consejo de Indias, dándole cuenta del envío de un memorial al licenciado Núñez y de algunos asuntos personales, entre ellos el fallecimiento de su madre y el de su primer hijo con Juana de Zúñiga", Texcoco, 10 de octubre de 1530, en Cortés, cartas y memoriales, documento 33, p. 192. Las cursivas son mías (N. de la A.).
} 
y de sustituir sus funciones si lo consideraba conveniente ${ }^{55}$. A decir de Aracil, en esos años el conquistador pasó de "leal consejero a molesto litigante", ya que envió numerosas cartas al rey Carlos en las que solicitaba el pago de sus servicios, daba concejos para la gobernación del virreinato, opinaba sobre el trato dado a los indígenas, pedía la intercesión del monarca en sus numerosos pleitos y trataba de mantener un vínculo que ya no era bien acogido por el destinatario de la correspondencia cortesiana ${ }^{56}$.

En 1541 participó en la batalla de Argel, con sus hijos Martín y Luis ${ }^{57}$. Esa batalla fue una derrota para España, tanto como para Cortés, que perdió cinco esmeraldas muy valiosas y que además fue ignorado cuando trató de sugerir estrategias de guerra. Derrotado y presa del desánimo, poco a poco dejó de embarcarse en pleitos, pero no desistió de escribir al rey para hacer recuento de sus servicios a la corona y pedir mercedes para sí. En 1542 le envió un memorial al emperador en el que nuevamente enumeraba las hazañas realizadas y los beneficios que ello había llevado al régimen imperial, e insinuaba que se había cansado de buscar al emperador sin obtener respuesta. Pedía que le regresaran lo que era suyo y hablando de sí mismo en tercera persona, terminaba diciendo que

a él se le ha quitado todo, no habiendo habido falta en su persona y gobernación, antes prefiriéndose a todos, porque aunque en esto él ha recibido mucho por quitarle del trabajo corporal y de peligro de su conciencia, no deja de estar afrentado, porque el vulgo no puede dejar de sospechar que pues siendo sus servicios tan notorios hay con él esta novedad, hay también una causa que sea bastante, la cual él no conoce, y suplica a Vuestra Majestad que si la hay se manifieste porque por ventura no será como a Vuestra Majestad le hayan informado, y dará descargo; y no le teniendo, conocerse ha que Vuestra Majestad le hace merced en perdonarle, y no es ingrato en no gratificarle ${ }^{58}$.

Un año más tarde, volvió a escribir al rey una carta en la que resaltaba los cuarenta años que había servido a la corona, después de haber acrecentado los reinos por sí y a sus expensas. Agradecía a Dios y afirmaba que al ser sus servicios "tan notables que jamás los hizo vasallo a su rey, y habiéndolos yo hecho al más católico y poderoso y agradecido de todos los reyes", esperaba que se le hiciera justicia y se le devolvieran los vasallos de los que había sido

\footnotetext{
55 Ibid., pp. 730-731.

56 Aracil, Yo, Don Hernando Cortés. [Edición electrónica].

57 Hay versiones que dicen que a Argel pudo ir Martín Cortés, pero no el heredero del marquesado, sino el hijo que Cortés tuvo con Malintzin y que llevó a España en 1528 para que fuera educado en la corte. Luis también era hijo natural. María del Carmen Martínez Martínez, Martín Cortés. Pasos recuperados (1532-1562), España, Centro de Estudios Mexicanos-UNAM España, El Forastero, 2017, pp. 39-41.

58 "Memorial de Hernán Cortés al emperador con relación de servicio y petición de mercedes", $c$. 1542, en Martínez, Documentos cortesianos IV, documento 281. [Edición electrónica].
} 
despojado. Pedía al rey que no le hiciera "tanto mal ni desventura", que no lo tuviera por "no cristiano ni temeroso de Dios". Además, le reclamaba que, en algún momento, el mismo Carlos le había dicho que "no había sido [suya] aquella conquista", agravio en el que a Cortés "le iba la honra", ya que aquel en cuyo nombre había actuado, no le reconocía las hazañas que había llevado a cabo siempre para gloria de la corona ${ }^{59}$.

La última carta de Hernán Cortés al emperador es conmovedora y amarga. Los desprecios recibidos, la sensación de haber sido ignorado por aquel a quien tanto dio, lo llevaron a reclamar abiertamente al rey el trato recibido en sus últimos años:

Pensé que el haber trabajado en la juventud, me aprovechara para que en la vejez tuviera descanso, y así ha cuarenta años que me he ocupado en no dormir, mal comer y as más de las veces ni bien ni mal, traer las armas a cuestas, poner la persona en peligros, gastar mi hacienda y edad, todo en servicio de Dios, trayendo ovejas a su corral muy remotas de nuestro hemisferio, e ignotas y no escritas en nuestras Escrituras, y acrecentando y dilatando el nombre y patrimonio de mi rey, ganándole y trayéndole a su yugo y real cetro muchos y muy grandes reinos y señoríos de muchas bárbaras naciones y gentes, ganados por mi propia persona y expensas, sin ser ayudado de cosa alguna, antes muy estorbado por nuestros muchos émulos e invidiosos que como sanguijuelas han reventado de hartos de mi sangre [...] porque no tengo ya edad para andar por mesones, sino para recogerme y aclarar mi cuenta con Dios, pues la tengo larga, y poca vida para dar los descargos, y será mejor perder la hacienda quel ánima $^{60}$.

La misiva incluye una elocuente nota final: "no hay que responder". Y la última carta enviada por Hernán Cortés al rey Carlos v quedó sin respuesta.

\section{Consideraciones finales}

Hernán Cortés murió en Castilleja de la Cuesta el 2 de diciembre de 1547. En su testamento encargó que llevaran sus restos a la Nueva España, disposición que se cumplió mucho más tarde. Tanto como él peregrinó en vida, así también sus huesos tuvieron un destino azaroso hasta su descanso final en la iglesia del Hospital de Jesús de Ciudad de México, en donde reposan hasta el día de hoy. Su relación con el emperador, que marcó su vida y su muerte, fue intensa y fructífera, aunque al final Cortés se sintió abandonado y mal pagado

59 "Carta de Hernán Cortés a Carlos v pidiéndole que lo favorezca en sus pleitos y no le haga tanto mal ni desventura", Madrid, 18 de marzo de 1543, en Martínez, Documentos cortesianos $I V$, documento 282. [Edición electrónica].

60 "Última carta de Hernán Cortés a Carlos v", Valladolid, febrero de 1544, en Martínez, Documentos cortesianos $I V$, documento 289. [Edición electrónica].

Araucaria. Revista Iberoamericana de Filosofí, Política, Humanidades y Relaciones Internacionales, año $23, \mathrm{n}^{\circ} 47$. Segundo cuatrimestre de 2021. Pp. 69-90. ISSN 1575-6823 e-ISSN 2340-2199 https://dx.doi.org/10.12795/araucaria.2021.i47.04 
a pesar de los grandes servicios prestados a la corona.

A decir de José Luis Martínez, a partir de 1529, cuando el emperador le negó el cargo de gobernador, "la política de la corona respecto a Cortés [fue] clara: a hombre y capitán tan excepcional como peligroso -como ya se ha dicho- era preciso honrarlo, distraerlo y anularlo, para que la Nueva España siguiera su camino" 61 . Así, la corona siempre alternó con él "el halago y el rigor, la concesión y la dilación, el honor y la reserva, como recursos necesarios para mantenerlo sujeto y evitar su desbordamiento"62. Al respecto, Beatriz Aracil afirma que su imagen de fiel vasallo no impresionó tanto al emperador Carlos v como "la de un conquistador capaz de alzarse con el poder en tierras tan alejadas de la península" ${ }^{63}$. No obstante, su capacidad política y su ideal de expandir las fronteras de la cristiandad, a decir de Esteban Mira Caballos, sólo podrán compararse con el mismo Carlos $\mathrm{V}^{64}$. Es decir, que el conquistador extremeño acabaría siendo una especie de alter ego del rey, cuyo afán por extender sus dominios encontró en Cortés a un gran seguidor de su política imperial.

En cuanto al vínculo que el conquistador desarrolló con el emperador, Cortés representó para el monarca la seducción de las novedades americanas y la de un héroe similar a los de los libros de caballerías, mientras que a Cortés lo sedujo el poder del joven convertido en rey a los dieciséis años. Ese vínculo personal, político y económico formó una estrecha relación en los años de la conquista ${ }^{65}$. Sin embargo, poco a poco, conforme se consolidó el poder real en la Nueva España, Hernán Cortés se convirtió en un súbdito incómodo, un personaje tan relevante que fue preciso acotar su poder e influencia y controlar su protagonismo y sus afanes de riqueza y aventura. Pero a pesar de ese ese final carente de la gloria que hubiese deseado, Cortés "ganó la eternidad", como afirma Esteban Mira Caballos. Se convirtió en el héroe de la conquista, creó su propio personaje capaz de realizar hazañas sin cuento, se presentó a sí mismo como un cristianizador y fiel vasallo, fue interlocutor del rey, se volvió famoso y su fama aún perdura, quinientos años después de los hechos de la conquista.

Cortés es un personaje paradójico en España y en México y su figura ha sido motivo de elogios y vituperios en las miles de páginas que se han escrito sobre él. No puede negarse que es un personaje fascinante, fundamental para comprender cómo ocurrió la conquista de México. Sus Relaciones no pueden obviarse cuando nos acercamos a los hechos de esos años y si bien cuenta sólo un lado de la historia, eso ha bastado para alimentar una vasta historiografía que sigue tratando de descifrar los acontecimientos de hace cinco siglos. Frente a una tendencia que busca desestimar la actuación de Hernán Cortés en la

\footnotetext{
${ }^{61}$ Martínez, Hernán Cortés, p. 819.

${ }^{62}$ Ibid., p. 821.

${ }^{63}$ Aracil, "El monarca, su vasallo y el otro", p. 157.

${ }^{64}$ Mira Caballos, op. cit. [Edición electrónica].

${ }^{65}$ Aracil, Yo, Don Hernando Cortés. [Edición electrónica].
} 
conquista y su protagonismo como actor central del drama, está la convicción de que, tal como afirma Patrice Gueniffey, "hay que aceptar que el cambio social es también obra de los actores, que los hombres hacen la historia, según un dicho común, unos hombres cuya libertad de actuar, si no es absoluta ni ilimitada por ser relativa, no deja de ser real" 66 .

En ese sentido, no se puede pensar la España de hoy sin la visión imperial de Carlos v, en la que Cortés jugó un papel central. La relación de ambos personajes, protagonistas de la historia en el siglo XVI, inventores de mundos nuevos, cristianizadores y transformadores, cambió el mundo entonces conocido. Para bien y para mal, no se puede entender la historia de España, ni la de México, por supuesto, sin conocer a quienes ayudaron a dar forma a ese proyecto imperial.

\section{Referencias bibliográficas:}

Aracil, Beatriz, "El monarca, su vasallo y el otro: Hernán Cortés y los vínculos de la escritura", en Sonia Mattalia, Pilar Celma y Pilar Alonso, eds., El viaje en la Literatura Hispanoamericana: el espiritu colombino, Valladolid, Iberoamericana Vervuert, 2008, pp. 147-157.

Aracil Varón, Beatriz, "Yo, don Hernando Cortés". Reflexiones en torno a la escritura cortesiana, Navarra, Iberoamericana-Veuvert, 2016. [Edición electrónica].

Cortés, Hernán, Cartas de relación, edición de Ángel Delgado, Barcelona, Castalia, 2016. , Cartas y memoriales, edición, estudio y notas María del Carmen Martínez Martínez, Valladolid, Consejería de Cultura y Turismo, León, Universidad de León, 2003.

Frankl, Victor, "Imperio particular e imperio universal en las cartas de Hernán Cortés" en Cuadernos Hispanoamericanos, 165 (1963), pp. 443-482.

Grunberg, Bernard, "Hernán Cortés: un hombre de su tiempo", en María del Carmen Martínez Martínez y Alicia Mayer, coords, Miradas sobre Hernán Cortés, Madrid, Iberoamericana-Veuvert, 2016, pp. 49-66.

Gueniffey, Patrice. "La voluntad en la historia". Istor: revista de historia internacional, 17 (2004), pp. 3-20. http://hdl.handle.net/11651/3494

Insua, Pedro, 1492. España contra sus fantasmas, Barcelona, Ariel, 2018. [Edición electrónica].

Kohut, Karl, "Hernán Cortés, héroe imperial”, en María del Carmen Martínez Martínez y Alicia Mayer, coords, Miradas sobre Hernán Cortés, Madrid, IberoamericanaVeuvert, 2016, pp. 67-85.

Leonard, Irving A., Los libros del conquistador, $2^{\mathrm{a}}$. ed., México, Fondo de Cultura Económica, 2006.

Martínez, José Luis, Hernán Cortés, México, 2a ${ }^{\text {a }}$ ed., Fondo de Cultura Económica, 2003. Martínez, José Luis, ed., Documentos cortesianos I 1518-1528. Secciones I a III, México, Fondo de Cultura Económica, UNAM, 2014 [Edición electrónica].

${ }^{66}$ Patrice Gueniffey, "La voluntad en la historia", Istor: Revista de historia internacional, 17 (2004), p. 4. http://hdl.handle.net/11651/3494

Araucaria. Revista Iberoamericana de Filosofia, Política, Humanidades y Relaciones Internacionales, año $23, \mathrm{n}^{\circ} 47$. Segundo cuatrimestre de 2021. Pp. 69-90. ISSN 1575-6823 e-ISSN 2340-2199 https://dx.doi.org/10.12795/araucaria.2021.i47.04 
Documentos cortesianos II 1526-1545. Sección IV. Juicio de Residencia, México, Fondo de Cultura Económica, UNAM, 2014 [Edición electrónica].

Documentos cortesianos III 1528-1532. Secciones V a VI $1^{a}$. parte, México, Fondo de Cultura Económica, UNAM, 2014. [Edición electrónica].

Documentos cortesianos IV 1533-1548. Secciones VI, $2^{a}$ parte a VIII, México, Fondo de Cultura Económica, UNAM, 2014 [Edición electrónica].

Martínez Martínez, María del Carmen, "Más pleitos que convenía a su estado", en María del Carmen Martínez Martínez y Alicia Mayer, coords., Miradas sobre Hernán Cortés, Madrid, Iberoamericana-Veuvert, 2016, pp. 87-118.

Martínez Martínez, María del Carmen, Martín Cortés. Pasos recuperados (1532-1562), España, Centro de Estudios Mexicanos-UNAM España, El Forastero, 2017.

Mira Caballos, Esteban, Hernán Cortés. Una biografía para el siglo XXI, Barcelona, Crítica, 2021. [Edición electrónica].

Miralles, Juan, Hernán Cortés. Inventor de México, México, Tusquets, 2001.

Pietschman, Horst, “El problema del 'nacionalismo' en España en la Edad Moderna. La resistencia de Castilla contra el emperador Carlos v”, en Hispania, 180 (1992), pp. 83-106.

Segundo Guzmán, Miguel Ángel, "Grafías del Conquistador: horizontes de significado señorial en las 'Cartas de relación' de Hernán Cortés” en Historia y Grafía, 23 (2016), pp. 177-209.

Trejo Rivera, Flor y Guadalupe Pinzón Ríos, “Tomas de posesión simbólicas de los espacios americanos: la manera de reclamar derechos sobre territorios recorridos $\mathrm{u}$ ocupados por los castellanos desde el siglo XVI", Noticonquista,

http://www.noticonquista.unam.mx/index.php/amoxtli/1323/1318. 